\title{
A Contribuição dos Recursos de Coesão para o Leitor Durante o Processo de Construção da Representação Textual
}

\author{
Antonia Barros Gibson Simões ${ }^{1}$; Henrique Miguel de Lima ${ }^{2}$;ilva Danielli Cristina de Lima Silva ${ }^{3}$; \\ Rita de Cássia Freire de Melo Vasconcelos ${ }^{4}$
}

\begin{abstract}
Resumo: Partindo do pressuposto de que, a partir de fragmentos do texto, o usuário da língua aplica estratégias para compreendê-lo (DIJK e KINTSCH, 1983), notamos que os conectivos podem influenciar na construção representacional do texto. A representação textual, construída durante a leitura (processamento) do texto, precisa ser coerente, neste sentido, os conectivos, existindo em função coerência textual, manifestam, explicitamente, como o leitor deverá relacionar os conteúdos dispostos em um texto, por isso devem ser relevantes para o leitor durante o processo de estabelecimento da coerência textual. A fim de refletirmos sobre a contribuição dos recursos de coesão durante a compreensão do texto, propomos, no presente trabalho, um diálogo entre os textos Strategies of Discourse Comprehension (DIJK e KINTSCH,1983) e The Semantics and Pragmatics of Functional Coherence in Discourse. (DIJK, 1980)- no que concerne à necessidade de construção representacional do texto- e a pesquisa psicolinguística sobre processamento textual, mais especificamente o processamento de conectivos, proposta e reportada por Sanders e Noordman e Vonk (1996). Por meio dos resultados encontrados pelos autores (NOORDMAN e VONK, 1996) percebemos contribuições- significativas estatisticamente- dos recursos de coesão, do tipo conectivos, durante o processamento textual que atestariam a relevância destes itens linguísticos na construção da representação mental do texto.
\end{abstract}

Palavras-chave: leitura, representação textual, processamento textual, recursos de coesão.

\section{The Contribution of Cohesion Resources for the Reader During the Construction Process of the Textual Representation.}

\begin{abstract}
Based on the fragments of the text, the user of the language applies strategies to understand it (DIJK and KINTSCH, 1983), we note that the connectives can influence the representational construction of the text. The textual representation, constructed during the reading (processing) of the text, must be coherent, in this sense, the connectives, existing in function of textual coherence, manifest, explicitly, how the reader should relate the contents arranged in a text, so they must be relevant to the reader during the process of establishing textual coherence. In order to reflect on the contribution of cohesion resources during the comprehension of the text, we propose in the present work a dialogue between the texts Strategies of Discourse Comprehension (DIJK and KINTSCH, 1983) and The Semantics and Pragmatics of Functional Coherence in Discourse. (Dijk, 1980) - with regard to the need for representational construction of the text - and the psycholinguistic research on textual processing, more specifically the connective processing proposed and reported by Sanders and Noordman and Vonk (1996). Through the results found by the authors (NOORDMAN and VONK, 1996) we perceive statistically significant contributions of the cohesive resources, of the connective type, during the textual processing that would attest the relevance of these linguistic items in the construction of the mental representation of the text.
\end{abstract}

Keywords: reading, textual representation, textual processing, cohesion resources.

\footnotetext{
${ }^{1}$ Doutoranda em Linguística - Universidade Federal da Paraíba - João Pessoa - PB, Pesquisadora do Laboratório de Processamento Linguístico da UFPB - LABROL/CNPQ Email: antoniagibson@ gmail.com

${ }^{2} 1$ Doutorando em Linguística - Universidade Federal da Paraíba - João Pessoa - PB, Pesquisador do VALPB/CNPQ Brasil. E-mail henrique.miguel.93@hotmail.com;

${ }^{3}$ Mestranda em Linguística pela UFPB. Pesquisadora do Laboratório de Processamento Linguístico da UFPB - LABROL/CNPQ. E-mail: limaanacrisdani@gmail.com

${ }^{4}$ Doutoranda em Linguística - Universidade Federal da Paraíba - João Pessoa - PB, Pesquisadora do Laboratório de Processamento Linguístico da UFPB - LABROL/CNPQ Email: ritafmv@ yahoo.com.br
} 


\section{Introdução.}

A leitura é uma tarefa que exige do leitor uma tentativa de compreender o texto. A compreensão é uma necessidade do usuário da língua, pois quando entendemos um texto podemos escrever e falar sobre o texto, conseguindo, satisfatoriamente, interagir e agir no mundo ${ }^{5}$. Assim, a leitura e a compreensão são processos equivalentes ou, como afirmou Marcuschi (2008, p.239), "ler equivale a ler compreensivamente”.

Ao operacionalizar a leitura de determinado texto, o leitor deverá construir, durante seu processamento, um novo texto, ou melhor, uma representação textual. Esta representação, que é a base da interpretação textual, é uma construção abstrata retida na memória e que permite ao leitor usar o texto compreendido de diversas formas. Entender o que influencia o processo de construção representacional do texto pode trazer informações relevantes sobre o processamento textual.

Assumindo a representação mental como uma interpretação sobre um evento, ou melhor, a construção de um significado para um texto (DIJK e KINTSCH, 1983), na hipótese construtivista, o usuário da língua, a fim de processar o discurso, fará uso de estratégias lançando mão de um processamento estratégico para construir uma representação mental do discurso na memória. No modelo estratégico o processamento do discurso é analisado "[...] a partir das unidades das palavras, até as unidades de temas gerais ou macroestruturais".(DIJK e KINTSCH,1983, p. 10) $)^{6}$.

Entendemos que os recursos de coesão, do tipo conectivo, influenciam o processo da construção representacional do texto, pois estes recursos, possuindo a função de manifestar explicitamente ao leitor como ele deverá relacionar os conteúdos existentes no texto (DIJK, 1980), devem auxiliar o leitor no momento em que este deve interpretar, de maneira global e coerente, as proposições contidas no texto. A representação textual deverá ser organizada de maneira a manifestar com coerência como as partes do texto se relacionam. Por exemplo, se o leitor lê um texto sobre a extinção de animais silvestres é possível que tente compreender as

\footnotetext{
${ }^{5}$ Ainda, segundo Marcuschi (2008, p.242), o sentido do texto será encontrado nas relações entre leitor, texto e autor, durante o processo de compreensão textual, neste sentido, o texto é visto como "[...] um evento comunicativo sempre emergente".

6 " [...] we will analyze discourse processing from the word units on the lower level, up to the unit of overall themes or macrostructures". "[...] vamos analisar o processamento do discurso das unidades de palavras no nível inferior, até a unidade de temas gerais ou macroestruturas " (tradução nossa) (DIJK e KINTSCH,1983, p. 10)
} 
causas para tal evento e, neste caso, operadores argumentativos com função causal (porque, pois, já que...) podem ajudar nesta tarefa.

O artigo está estruturado da seguinte forma: começaremos escrevendo sobre a representação mental do texto com base nas contribuições teóricas de Dijk e Kintsch (1983) e Dijk (1980) observando o papel dos conectivos no processamento estratégico.

Logo depois relataremos uma pesquisa psicolinguística sobre o processamento de diversos conectivos com funções de coerência do tipo problem-solution e list, e, em seguida, proporemos um diálogo entre modelo estratégico de discurso e processamento linguístico, por meio da realidade psicológica do estabelecimento da estratégia da coerência local, que acontece quando o leitor procura links para relacionar as partes constituintes o texto. Por fim, na conclusão, refletiremos sobre a importância dos conectivos na criação de uma representação adequada do texto, observando o leitor como um sujeito criador ou construtor textos fundamentados em interpretações daquilo que foi lido (processado). Além disso, propomos, de forma incipiente, uma reflexão sobre os benefícios de aplicações práticas de conteúdos, em sala de aula, sobre os recursos de coesão do tipo conectivos.

\section{A representação mental do texto e o modelo estratégico do processamento.}

A construção de uma representação mental de um texto, segundo DIJK e KINTSCH (1983), é uma tentativa de atribuição de significado ao texto e acontece enquanto o usuário da língua está processando o texto. Os autores afirmam que o processamento (produção/compreensão) do discurso exige a construção de uma representação mental, na memória, e para a realização desta construção o usuário da língua usará informações externas e internas tendo como objetivo "ser o mais efetivo possível na construção da representação mental"7, assim, o processamento de um discurso seria estratégico.

A partir de fragmentos do texto (unidades menos complexas), o usuário da língua aplicará estratégias, definidas, segundo os autores, como hipóteses efetivas sobre a estrutura e significados corretos de um texto. Basicamente o modelo estratégico admite que, por causa das

\footnotetext{
${ }^{7}$ Aqui passaremos a entender discurso como texto.

"We see that persons have the ability to flexibly make use of various kinds of information, [...] and that the overall goal of-the process is to be as effective as possible in the construction of the mental representation." (DIJK e KINTSCH,1983, p. 6) 
limitações da memória de trabalho, a partir do estabelecimento das relações entre as sentenças, a informação "velha" é transferida para a memória episódica, de onde pode ser recuperada imediatamente se for necessária ao estabelecimento da coerência de sentenças posteriores. Assim, o leitor relacionará as informações velhas (já lidas) às informações novas (que estão sendo lidas) para chegar à conclusão de que o texto é coerente (DIJK, 1980).

Um dos componentes do modelo estratégico de interpretação do discurso é a estratégia da coerência local. Deteremo-nos neste componente por se relacionar diretamente com a função dos conectivos na superfície textual.

A estratégia da coerência local é responsável pelo estabelecimento das conexões de significado entre várias sentenças (DIJK e KINTSCH,1983, p. 14) ${ }^{8}$. A construção da coerência local exige, do usuário da língua, uma busca por links potenciais entre fatos refletidos nas proposições. Os usuários podem usar diversas estratégias de coerência local: repetição do argumento, uso de determinada ordem nas orações, uso de conectivos explícitos... O conhecimento retido na memória de longo prazo fornecerá, ao usuário da língua, as maneiras com as quais as proposições deverão ser conectadas ao longo do texto (DIJK e KINTSCH,1983). A coerência local, componente do modelo semântico de interpretação do discursos, se relaciona com outro componente: a macroestratégia.

As macroestratégias têm por características serem flexíveis e heurísticas (DIJK e KINTSCH,1983). Ao tentar "descobrir" o que o texto quer "dizer" o usuário da língua tentará inferir, antes mesmo de terminar a leitura, o sentido do texto. Assim, é capaz de fazer suposições sobre o texto, a partir de informações mínimas. Estas suposições são fundamentadas na estrutura superficial do texto e no conhecimento de mundo do leitor do texto (DIJK e KINTSCH,1983).

O leitor pode, por exemplo, construir uma hipótese efetiva sobre elementos referenciais de um texto a partir do título: A crise do magistério público brasileiro. Neste caso, o leitor, provavelmente, esperará encontrar elementos referenciais como professor, profissão docente, a remuneração, políticas públicas... É provável que o leitor não tenha colocado na lista de elementos referenciais os itens linguísticos gato, pássaros, nem tenha construído hipóteses efetivas fundamentados em relações semânticas entre estes itens pois eles não fazem parte do que se espera em um evento linguístico tratando do magistério no Brasil.

\footnotetext{
8 “[...] establishment of meaningful connections between successive sentences in a discourse." (DIJK e KINTSCH,1983, p. 14)
} "[...] estabelecimento de conexões significativas entre sentenças sucessivas em um discurso". (tradução nossa). 
A coerência local, aspecto crucial para a compreensão de um texto, segundo Dijk (1980, p.4) define-se, basicamente, pelas relações entre sentenças de uma sequência textual. Os textos expressam fatos, ou seja, fragmentos de mundos possíveis. Estes fatos podem ser conectados, caso haja relação entre eles. Os conectivos são importantes, estrategicamente, para a compreensão de um texto pois “[...] são os mais eficazes sinais para manifestar a relação entre os fatos", sendo fundamentais para o estabelecimento da coerência, já que os leitores precisam relacionar os fatos em sua totalidade e, para isso, o estabelecimento de correferência ou antecipação de consequências dos fragmentos de textos não são suficientes para a compreensão do texto como um todo (DIJK, 1980, p.11) ${ }^{9}$. O texto deverá fornecer pistas, explícitas ou implícitas, ao leitor para que este saiba como deverá relacionar as proposições textuais.

O resultado final da compreensão do texto seria uma representação adequada (coerente) do significado do texto. Esta representação textual, segundo Dijk (1980), é comparada a um retrato do mundo (world picture). Os leitores, durante a compreensão de um texto mapeiam os diversos retratos de mundo, utilizando, também, informações contextuais e conhecimento de mundo geral; os diversos textos que os leitores lêem podem ser iguais ou similares a outros retratos de mundo que já estão "arquivados" na memória de longo prazo do leitor. Estes retratos de mundo são, então, recuperados ou atualizados no processo de construção da representação semântica do texto lido (DIJK, 1980) .

A coerência local, neste processo de construção da representação textual, é responsável pelo estabelecimento da coerência do texto. Neste sentido, a estratégia para a realização da compreensão textual é, segundo Dijk (1980) assumir que as partes compositoras do texto são coerentes, portanto, cada nova oração ou sentença, depois de interpretada, é relacionada à sentença anterior. A existência desta relação permite ao leitor concluir que o texto é coerente, entretanto como o leitor executa ou operacionaliza a estratégia da coerência textual? Vejamos, como isto acontece, por meio de exemplos.

A identificação dos participantes de um texto é um exemplo de estratégia de coerência local, ou seja, neste caso, os leitores utilizam a informação contida na superfície textual. A

\footnotetext{
9 “[...] Strategically, connectives are very important. Neither identical participants nor possible consequences as such are sufficient for the establishment of Coherence : what we need is a relation between the FACTS as wholes; and the connectives, all other things being equal, are the most effective signals for the nature of this relationship between the facts (the FACTS in WR)." "Estrategicamente, os conectivos são muito importantes. Nem participantes idênticos (correferentes) nem conseqüências possíveis (antecipação textual), como tais, são suficientes para o estabelecimento da Coerência: o que precisamos é uma relação entre os FACTOS como todo; e os conectivos, sendo todas as outras coisas iguais, são os sinais mais eficazes para a natureza dessa relação entre os fatos (os FATOS em uma representação de mundo possível)" (tradução nossa).
} 
estratégia deste tipo é fundamentada em análises hipotéticas, que podem ser revisadas, quando da leitura de novos trechos do texto.

Outra estratégia é identificação dos predicados do trecho que está sendo lido. Uma vez que o sujeito da proposição 1, por exemplo, tenha aparecido novamente na proposição 2, é relevante identificar o estado, o evento, ou a ação em que o participante do texto está envolvido (DIJK, 1980). Além disso, nesta identificação, o leitor deverá perceber se o predicado é uma consequência do que aconteceu na sentença anterior e se a sentença anterior é uma condição necessária, provável ou possível para o evento que está sendo lido. Aqui o autor afirma a importância dos conectivos neste tipo de estratégia porque os conectivos manifestam a natureza da relação entre os fatos.

Os leitores assumem, durante a leitura de um texto, que uma sequência textual pode ser relacionada coerentemente com a sentença anterior, portanto, um instrumento manifestando explicitamente como as partes do texto devem ser relacionadas, possivelmente, ajuda o leitor a construir uma representação textual adequada.

Se o leitor tem conhecimento de mundo sobre o assunto tratado na sentença e reconhece a função do conectivo utilizado para estabelecer a relação entre as proposições do texto, provavelmente interpretará o texto com coerência (DIJK, 1980).

\section{A influência do conectivo na compreensão textual.}

Sanders e Noordman (2000) investigaram o papel da coerência e de seus marcadores linguísticos no processamento textual. Segundo os autores, a compreensão de um texto exige a construção representacional do texto. Esta representação tem como princípio ser coerente. $\mathrm{O}$ estabelecimento da coerência se dá por meio das relações entre as partes compositoras do texto. As relações de sentido que conectam duas partes do texto são chamadas relações de coerência, vejamos um exemplo (SANDERS \& NOORDMAN, 2000,p. 38):

(1) It must be a buzzard. It is soaring high in the air ${ }^{10}$.

10 "Deve ser um urubu. Ele está subindo alto no ar". 
Para os autores, a segunda proposição da sentença (1), It is soaring high in the air, é um argumento para a afirmação contida na primeira proposição: It must be a buzzard. Por isso esta relação entre conteúdos é chamada de afirmação-argumento (claim-argument).

Os autores investigaram a natureza da relação de coerência e a maneira como estas relações são manifestadas (explicitamente ou implicitamente). Vejamos outro exemplo de relação de coerência implícita entre as partes de um texto (SANDERS \& NOORDMAN, 2000,p. 38) ${ }^{11}$ :

Figura 1: relação de coerência do tipo problem-solution. Na primeira parte da sentença temos exposto o problema, na segunda parte temos a solução para o problema.

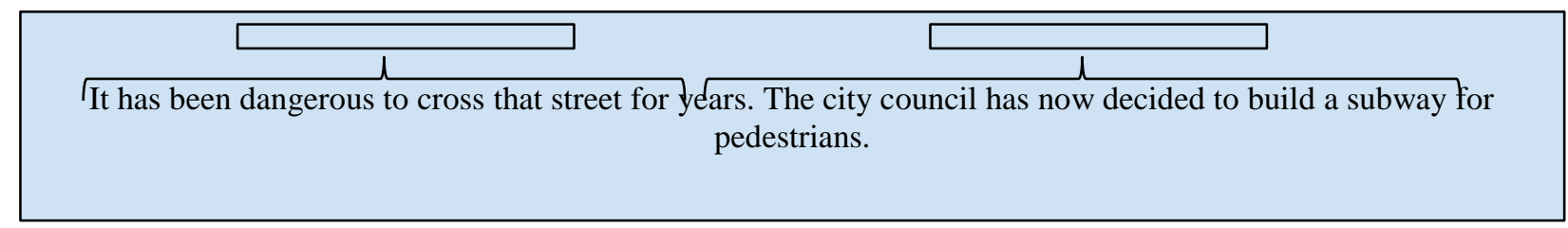

Fonte: elaboração própria

A figura 1 demonstra uma relação de coerência não marcada explicitamente, entretanto uma expressão conectiva ou mesmo um conectivo poderiam, de maneira marcada, indicar o tipo de relação de coerência intencionada pelo autor do texto, no caso, a relação seria problemasolução (problem-solution):

(2) It has been dangerous to cross that street for years. There is a solution for this problem: the city council has now decided to build a subway for pedestrians ${ }^{12}$. $39)^{13}$

Vejamos outro tipo de relação de coerência (SANDERS \& NOORDMAN, 2000,p.

\footnotetext{
11 "Tem sido perigoso atravessar aquela estrada por anos. A assembleia da cidade decidiu agora construir uma passagem subterrânea para os pedestres" (tradução nossa).

12 "Tem sido perigoso atravessar essa rua por anos, há uma solução para este problema: o conselho municipal decidiu agora construir um metrô para pedestres." (tradução nossa)

13 "A assembleia da cidade resolveu construir uma passagem subterrânea para os pedestres. Novos sinais de trânsito serão instalados nas redondezas". (tradução nossa)
} 
Figura 2: Exemplo de relação de coerência do tipo lista (list)

The city council has decided to build a subway for pedestrians. New traffic lights will be installed nearby.

Fonte: elaboração própria

As partes da sentença com a relação de coerência do tipo list podem ser linguisticamente marcadas com itens linguísticos como "in addition..." ou mesmo com "also..." manifestando explicitamente este tipo de relação de coerência ${ }^{14}$ :

(3) The city council has decided to build a subway for pedestrians. In addition new traffic lights will be installed nearby.

Os autores elegeram as relações problema-solução e lista para investigar o processamento da coerência textual. Relatamos, nas tabelas 1 e 2 , respectivamente, as características destes tipo de relação de coerência entre as partes do texto, assim como seus marcadores textuais explícitos utilizados no experimento (SANDERS \& NOORDMAN, 2000,p. 43-44):

Tabela 1: As características marcantes observadas pelos autores na investigação sobre as relações de coerência entre as partes de um texto:

\begin{tabular}{|c|c|}
\hline $\begin{array}{c}\text { RELAÇÃO DE COERÊNCIA PROBLEM- } \\
\text { SOLUTION }\end{array}$ & RELAÇÃO DE COERÊNCIA LIST \\
\hline Relação causal & Relação de adição \\
\hline Conexão mais forte entre os segmentos & Conexão menos forte entre os segmentos \\
\hline $\begin{array}{l}\text { Relação complexa: existe uma situação negativa } \\
\text { que requer uma ação que elimine a situação } \\
\text { negativa. } \\
\text { É uma relação causal: } \\
\text { "Por causa da sentença } 1 \text {, sentença } 2 \text { "; } \\
\text { "Sentença 1. Por consequência, sentença 2". }\end{array}$ & $\begin{array}{l}\text { Diferentes aspectos são relacionados como em } \\
\text { uma listagem. }\end{array}$ \\
\hline
\end{tabular}

Fonte: elaboração própria.

14 “Além disso..."; "também...". 
Tabela 2: formas explícitas de marcadores linguísticos utilizadas no experimento ${ }^{15}$.

\begin{tabular}{|l|l|}
\hline \multicolumn{1}{|c|}{ PROBLEM-SOLUTION } & \multicolumn{1}{c|}{ LIST } \\
\hline because & and \\
\hline therefore & also \\
\hline The problem is... & next \\
\hline The solution is... & furthermore \\
\hline To prevent that... & In addition... \\
\hline & Another aspects... \\
\hline & That is not all... \\
\hline & Others things can be added to this \\
\hline
\end{tabular}

Fonte: elaboração própria.

Vejamos exemplos das sentenças experimentais utilizadas pelos autores (SANDERS \& NOORDMAN, 2000,p.45) ${ }^{16}$ do tipo problem-solution e list, respectivamente:

(4) Another inhabitant of Veendam was killed in a traffic accident yesterday. The man crossed the street and was hit by a truck. For years the people of Veendam have now been campaigning to reduce the annoyance caused by the traffic in their town. This annoyance is caused especially by freight traffic that passes through the heart of the town. Because of the heavy traffic, crossing the street has become very dangerous.

Sentença alvo:

(A solution is in sight now) The construction of a subway in the center of Veendam will begin next year. This was decided at a meeting of the city council. When the subway is finished, pedestrians and cyclists will be able to cross the road safely ${ }^{17}$.

\footnotetext{
${ }^{15}$ Marcadores explícitos do tipo problema-solução, na ordem em que aparecem na tabela:"porque";"'assim sendo"; “o problema é..."; "a solução é..."; "Para evitar que..."

Marcadores explícitos do tipo lista, na ordem em que aparecem na tabela: "e"; "também"; "em seguida"; "além disso"; "Além do que, além do mais..."; "Outro aspecto ..."; "Isso não é tudo ..."; "Outras coisas podem ser adicionadas a este...”. (tradução nossa)

${ }^{16}$ Interessante notar que nas versões com marcadores relacionais explícitos os marcadores antecederam imediatamente a sentença alvo, enquanto na versão implícita os marcadores não foram incluídos antes da sentença alvo.

17 "Outro habitante de Veendam foi morto em um acidente de trânsito ontem. O homem atravessou a rua e foi atingido por um caminhão. Durante anos, as pessoas de Veendam estão fazendo campanha para reduzir o aborrecimento causado pelo trânsito na cidade. Esse aborrecimento é causado principalmente pelo tráfego de mercadorias que atravessa o coração da cidade. Por causa do tráfego pesado, cruzar a rua tornou-se muito perigoso.
} Sentença alvo: 
(5) The traffic in the region of East Groningen will be having trouble the next year because of road construction. Especially in Veendam and its surroundings road construction will be going on. A new local road will be constructed between the towns of Stadskanaal and Veendam. The exit of the highway between Groningen and German border, on the east of Veendam, will be re-asphalted in spring.

Sentença alvo:

(A third project is situated nearby) The construction of a subway in the center of Veendam will begin next year. This was decided at a meeting of the city council. When the subway is finished, pedestrians and cyclists will be able to cross the road safely ${ }^{18}$.

Os sujeitos participantes do experimento realizaram três tarefas: leitura de sentenças; verificação de informações contidas no texto e tarefa de recall.

A leitura de sentença foi realizada por meio da tarefa online de leitura automonitorada. Neste tipo de método o participante fica em frente a tela do computador, lendo as partes do texto, ou seja, o texto aparece segmentado. Para ler a primeira parte do texto o leitor pressiona determinada tecla, do computador, depois da leitura, aperta de novo a mesma tecla e o segmento lido desaparece ficando o novo segmento do texto na tela; o leitor deverá proceder da mesma maneira até terminar de ler todo o texto.

A tarefa de verificação de informação consistiu em ler afirmações sobre o texto e responder se a afirmação era correta e ou incorreta por meio de botões que correspondiam às respostas.

$\mathrm{Na}$ tarefa de recall o participante tinha que escrever tudo que se lembrasse de um dos vinte textos lidos por ele.

O tempo de leitura registrado, no computador, era baseado no momento em que o segmento aparecia na tela até o momento em que o leitor teclava para ler o segmento seguinte.

(Uma solução está à vista agora) A construção de um metrô no centro de Veendam começará no próximo ano. Isto foi decidido em uma reunião do conselho da cidade. Quando o metrô estiver terminado, pedestres e ciclistas poderão atravessar a estrada com segurança." (tradução nossa).

18 "O tráfego na região de East Groningen terá problemas no próximo ano devido à construção de estradas. Especialmente em Veendam e seus arredores, a construção de estradas estará em andamento. Uma nova estrada local será construída entre as cidades de Stadskanaal e Veendam. A saída da estrada entre Groningen e a fronteira alemã, a leste de Veendam, será reasfaltada na primavera.

Sentença alvo:

(Um terceiro projeto está situado nas proximidades) A construção de um metrô no centro de Veendam começará no próximo ano. Isto foi decidido em uma reunião do conselho da cidade. Quando o metrô estiver terminado, pedestres e ciclistas poderão atravessar a estrada com segurança”. (tradução nossa). 
Já o tempo de resposta era registrado com base no momento em que aparecia a afirmação sobre o texto até quando o leitor apertava o botão com a resposta correspondente.

As variáveis independentes do experimento foram as relações de coerência (problemsolution e list) e seus marcadores linguísticos (explícitos e implícitos) ${ }^{19}$.

Os autores encontraram efeito significativo para o tipo de relação de coerência, ou seja, houve menores tempos de leitura para sentenças alvo tipo problem-solution quando comparados ao tempo de leitura para sentença alvo de sentenças tipo list. Houve, também efeito relacionado à existência de marcador linguístico relacional, pois o tempo de leitura para a sentença alvo na condição com marcador linguístico relacional implícito foi maior do que tempo de leitura para sentença alvo na condição com marcador relacional explícito. Não encontraram efeito de interação entre relação de coerência e marcador linguístico. Isto significa que, independente do tipo de relação de coerência, seja problem-solution ou list, a existência do marcador relacional facilitou a leitura dos sujeitos participantes da pesquisa. Além disto, independente da existência do conectivo, a relação de coerência do tipo problem-solution, foi lida mais rapidamente do que textos contendo relações de coerência do tipo list.

Também sobre os resultados encontrados, na tarefa de verificação os textos contendo a relação de coerência problem-solution foram verificados mais rapidamente e com mais precisão (mais acerto).

Com relação à tarefa de recall é importante reportarmos algumas informações. O recall foi analisado qualitativamente e quantitativamente. No primeiro caso, os autores observaram se os sujeitos participantes do experimento escreveram sobre o texto lido de maneira a manifestar a relação de coerência contida nele, por exemplo: em textos problem-solution, aceitavam-se paráfrases contendo o conectivo therefore. No segundo caso, a análise recaia sobre a quantidade de elementos ou palavras contidas na sentença alvo que o leitor conseguisse reproduzir.

Os resultados sobre a tarefa de recall mostraram que para o recall quantitativo a existência de marcador relacional não influenciou significativamente a quantidade de informação reproduzida. Entretanto, na análise qualitativa da tarefa de recall houve efeito da relação de coerência contida no texto, assim, a relação de coerência do tipo problem-solution foi mais relembrada do que quando o texto continha relação de coerência do tipo list.

\footnotetext{
${ }^{19}$ As variáveis independentes de um experimento são os elementos manipulados pelo realizador experimento psicolinguístico. 
Uma vez estabelecida uma representação do texto, a relação de coerência problemsolution foi mais facilmente acessada e reproduzida. Neste sentido, segundo os autores, parece que a relação problem-solution resulta em uma representação cognitiva do texto mais forte (relação causal) do que a representação formada por uma relação tipo list, por isso as afirmações sobre o texto com relação de coerência do tipo problem-solution foram verificadas mais rapidamente, e com menor quantidade de erros.

Além disso, como a primeira parte da relação de coerência do tipo problem-solution apresenta um problema, a expectativa natural do leitor é encontrar uma solução, assim, a parte do texto com a solução será lida mais rapidamente porque era um resultado esperado. Os textos com relação de coerência do tipo list não contaram com esse tipo de expectativa.

Os autores esperavam que as sentenças alvo de textos com estrutura manifestando a relação de coerência do tipo problem-solution fossem reproduzidas (recall quantitativo) mais frequentemente do que as sentenças alvo de texto com relação de coerência do tipo list. Os resultados mostraram que a existência do marcador conduziu a um processamento mais rápido da parte do texto em que estava contido, entretanto não influenciou na tarefa de recall cuja análise foi quantitativa. Por isso, os autores afirmaram que a influência do marcador ocorre online durante o processamento e decresce com o tempo, ocorrendo o contrário com as relações de coerência (SANDERS \& NOORDMAN, 2000).

Diferentes relações de coerência são processadas de maneira diferente, ou seja, segundo os autores, os leitores fazem uso de um conjunto limitado de primitivos cognitivos para estabelecer as relações de coerência entre partes do texto; os resultados mostraram que a relação causal é um tipo de relação que influencia o processamento do texto (SANDERS \& NOORDMAN, 2000). A existência de marcadores linguísticos relacionais parece promover um processamento mais rápido do segmento que o segue, entretanto, a falta de um marcador relacional não afetou significativamente a tarefa de recall (quantitativa).

Os autores expõem que existe uma interação entre a informação contida no texto e o leitor. Assim, na relação causal a compreensão do texto passa pela tentativa do leitor de buscar as causas para determinados eventos; a primeira tentativa do leitor ao ler um texto é, portanto, estabelecer uma relação causal. E o leitor será afetado pelo seu conhecimento esquemático, ou seja, a estrutura do texto poderá desencadear expectativas a respeito de passagens do texto. Neste caso, se o texto descreve um problema a expectativa forte é de que mais adiante haverá a solução de um problema. 
Os resultados mostraram que a representação textual fundamentada na relação causal é mais facilmente acessada e mais facilmente reproduzida. Mas e os marcadores textuais, qual a sua influência no processamento do texto?

Houve efeito de marcador linguístico na tarefa de verificação do texto, que requer acesso à representação textual feita imediatamente após a leitura do texto, entretanto não houve efeito significativo para a existência do marcador linguístico explícito nas tarefas de recall (na análise quantitativa). Parece, portanto, que a influência do marcador relacional decresce com o tempo, o contrário, segundo os autores, ocorre com o tipo de relação de coerência.

O leitor ao ler um texto cria uma representação textual superficial. Esta representação é fortemente influenciada pelos marcadores linguísticos relacionais explícitos. A vantagem do texto com marcador relacional explícito, entretanto, é temporária. O que perdura, com o tempo, é o tipo de relação de coerência (ou a informação relacional). Neste ponto do processamento, a essência do texto é arquivada e, depois de outras tarefas experimentais, a tarefa de recall é influenciada por este ponto do processamento.

\section{A realidade psicológica do processamento estratégico.}

Segundo Dijk (1980), uma das estratégias assumidas pelo leitor é a de que as proposições contidas no texto são coerentes. Por isso, cada proposição lida, depois de interpretada, deverá ser relacionada àquelas já lidas. Assim, pensemos na metáfora da colcha de retalhos: vários retalhos reunidos manifestam a unidade da colcha. Da mesma forma, várias proposições reunidas manifestam a unidade do texto. $\mathrm{O}$ tecelão parte da premissa de que os retalhos deverão ser reunidos para formar uma colcha, por isso, ele costura os retalhos. O leitor parte da premissa de que as proposições deverão formar um texto, por isso, ele lança mão de estratégias, que são operações cognitivas, para reunir (costurar) as proposições que formarão o texto.

Como vimos anteriormente, o processo de relacionar as informações de um texto, envolve, também, operações cognitivas fundamentadas nas partes manifestadas superficialmente no texto, como a identificação dos participantes, identificação dos predicados, a identificação de conectivos. Neste ponto, a título de exemplificação, vejamos um trecho de um artigo sobre a formação dos professores no Brasil (GATTI, p.1375, 2010): 
(6) "No que concerne à formação de professores, é necessária uma verdadeira revolução nas estruturas institucionais formativas e nos currículos da formação. [...] A formação de professores não pode ser pensada a partir das ciências e seus diversos campos disciplinares, como adendo destas áreas, mas a partir da função social própria à escolarização - ensinar às novas gerações o conhecimento acumulado e consolidar valores e práticas coerentes com nossa vida civil."

Percebemos que a autora ao repetir elemento referencial formação dos professores poderá levar o leitor a fazer conexões entre os predicados formadores dos trechos em que este item referencial está inserido. Da mesma forma, a leitura do conectivo mas poderá auxiliar o leitor a perceber que a formação dos professores tem uma função social e esta característica deve prevalecer sobre as demais. Podemos considerar que o conectivo tem a função de auxiliar o leitor na interpretação deste parágrafo, entretanto, como verificar a realidade psicológica da contribuição dos conectivos durante a leitura de um texto?

Experimentos psicolinguísticos, por meio de tarefas experimentais podem acompanhar o comportamento linguístico do leitor no momento da leitura de um texto ${ }^{20}$. Assim, quando Sanders e Noordman (2000) encontraram maiores tempos de leitura quando o marcador relacional ou conectivo estava implícito quando compararam com o tempo de leitura para trechos do texto com marcador relacional explícito, percebemos que a leitura foi facilitada quando o conectivo esteve presente informando ao leitor a forma como ele deveria relacionar as proposições formadoras do texto, independente do tipo de marcador: tanto aqueles referentes à relação problem-solution, quanto à relação list promoveram menores tempos de leitura para os trechos em que estavam inseridos no texto. Aqui percebemos a importância dos conectivos, na estratégia de coerência local, por meio dos menores tempos de leitura para os textos contendo os conectivos.

Além disto, o tipo de relação de coerência pareceu afetar a forma como o leitor constrói sua representação mental do texto. A relação problem-solution fundamenta uma representação mais forte, pois ela foi mais facilmente acessada, quando da tarefa de verificação de texto, e mais facilmente reproduzida (na tarefa de recall com análise qualitativa). Aqui percebemos a importância da criação das hipóteses efetivas sobre o texto. Quando o leitor se depara com um texto cuja primeira proposição aponta um problema, o leitor, provavelmente, esperará encontrar

\footnotetext{
${ }^{20}$ As tarefas que registram o tempo de leitura no exato momento em que o leitor está lendo o texto são chamadas de tarefas experimentais online. 
uma solução na próxima proposição a ser lida. Por isso, menores tempos de verificação sobre afirmações sobre textos contendo a relação problem-solution, além de maior quantidade de reprodução de relações de coerência deste tipo, quando comparadas às mesmas tarefas para textos com relação de coerência tio list.

A partir dos resultados encontrados pelos autores (SANDERS e NOORDMAN, 2000) parece, portanto, que a influência dos conectivos no processo de construção representacional do texto é real psicologicamente.

É possível que os conectivos auxiliem na criação da representação superficial do texto, sendo esta considerada uma representação ainda em movimento ou não acabada. Entretanto, a representação final do texto parece ser mais influenciada pelo tipo de relação de coerência, e, neste caso, a influência do conectivo é menor ${ }^{21}$.

Se os leitores, utilizando a estratégia da coerência local, procuram links para relacionar as partes de um texto, então a existência deste link deverá ajudar o leitor na consecução da sua representação mental, ainda que seja no momento da construção de uma representação textual superficial, ou inicial, o que foi demonstrado pelos resultados encontrados por Sanders e Noordman (2000).

\section{Conclusão}

Assumimos, neste trabalho, que a compreensão textual exige a construção da representação mental do texto. Portanto, quando um leitor entende um texto significa que houve um processo de atribuição de sentido àquilo que foi processado. A capacidade de falar e escrever sobre determinado assunto deve estar apoiada em alguma construção mental, ou seja, um componente abstrato, cujas atribuições (características essenciais) são retidas na memória, portanto, esta construção abstrata representa os aspectos mais relevantes selecionados pelo leitor do texto.

\footnotetext{
${ }^{21}$ Percebamos, ainda, que a existência do conectivo para manifestar um tipo de relação de coerência não é obrigatória. Antunes (2010, p.141) mostra explicitamente esta característica em seu texto: “[...] Uma consideração que me parece pertinente tem a ver com o fato de que os valores semânticos dessas relações (de oposição, de causalidade, de consequência etc.) podem ser expressos por outros recursos que não são expressões conectoras. Por exemplo, uma relação de causa e efeito pode estar significada por um verbo, como 'decorrer', 'resultar', 'provir' etc. Também vale a pena notar as relações semânticas possibilitadas pelas chamadas orações reduzidas”.
} 
Assumimos, também, que o leitor precisa se apoiar em aspectos superficiais do texto, entretanto, sua tentativa de compreensão vai além desta parte superficial reunindo outros tipos de informações como, por exemplo, aquelas que fazem parte do conhecimento de mundo do leitor. A estrutura superficial do texto unida ao conhecimento de mundo do leitor formarão a fundamentação para a interpretação adequada de um texto.

Tentamos demonstrar, por meio de experimento psicolinguístico, a contribuição dos conectivos no processo de construção da representação mental do texto. Percebemos, também, que parecem ser reais psicologicamente as estratégias utilizadas pelo leitor para compreender o texto. O usuário da língua tentará ser o mais efetivo possível utilizando, ou pondo em funcionamento, sua habilidade de usar flexivelmente as informações relevantes para seu objetivo principal: entender o texto.

A existência do conectivo é relevante para o processamento textual pois ele poderá auxiliar o leitor no processo de criação das suposições sobre o texto, além de mostrar explicitamente como o leitor deve relacionar os conteúdos do texto. As primeira tentativas de feitura de suposições parecem ser influenciadas pela existência do conectivo. Por isso, encontramos menores tempo de leitura para textos com conectivos, entretanto, o conhecimento retido na memória de trabalho mostrará ao leitor como ele deverá relacionar coerentemente as proposições contidas no texto. Neste caso, o leitor parece guardar na memória a relação de coerência já experenciadas, não necessariamente o conectivo. Vejamos as sentenças:

(7) Trabalho, trabalhou, não ganhou nada.

(8) Trabalhou, trabalhou, mas não ganhou nada.

No texto (7) não existe o conectivo para fundamentar as relações entre as proposições existentes. No texto (9) existe a forma canônica de valor opositivo, contrastivo ou adversativo representado pelo conectivo mas. O que quisemos demonstrar por meio de tarefa experimental é que o leitor, provavelmente, chegará a uma representação textual final que manifeste a relação de coerência proposta pelo autor do texto contanto que ele tenha conhecimento sobre estas relações. Portanto, podemos afirmar que o leitor, depois da leitura dos textos 7 e 8 , deverá perceber uma contradição: é normal que quem trabalhe muito receba alguma coisa por isso. Entretanto os textos 7 e 8 “dizem” o contrário: quem trabalhou não recebeu nada. Fazendo uma correlação com os resultados do experimento observamos que os leitores, provavelmente, 
construiriam mais facilmente a representação textual superficial quando lessem os texto 8, pois os conectivos auxiliariam explicitamente a tarefa de relacionar os conteúdos. Mas, depois de algum tempo, o que ficaria retido na memória é a relação de oposição entre as proposições.

Se o leitor constrói um novo texto a partir do que acabou de ler, é relevante sua experiência com diversos tipos de textos com diversas relações de coerência e seus marcadores textuais, caso contrário, não poderá construir uma representação mental do texto adequada. Ainda podemos refletir sobre a contribuição dos conectivos no âmbito do aprendizado escolar: em sala de aula poderá ser benéfico o trabalho com conectivos, em funcionamento nos textos, não em listas de classificações para serem memorizadas, pois quando estão manifestados explicitamente no texto auxiliarão os alunos na construção mental da sua representação textual, logo em momentos iniciais, facilitando assim, a percepção sobre os sentidos do texto.

\section{Referências}

DIJK, Teun A. Van. The Semantics and Pragmatics of Functional Coherence in Discourse. Disponível em:http://citeseerx.ist.psu.edu/viewdoc/download?doi=10.1.1.651.5552\&rep=rep1\&type=pdf Acesso em:03/08/2017.

DIJK, Teun A. van; KINTSCH, Walter. Strategies of Discourse Comprehension. Disponível em:http://citeseerx.ist.psu.edu/viewdoc/download?doi=10.1.1.473.5491\&rep=rep1\&type=pdf Acesso em:18/12/2017.

GATTI, Bernadete A. Formação de professores no Brasil: características e problemas. Disponivel em: http://www.scielo.br/pdf/es/v31n113/16.pdf Acesso em:13/04/018.

NOORDMAN, L.G.M.; VONK, W. The different functions of a conjunction in constructing a representation of all discourse. In Costermans \& Fayol (Eds.), Processing interclausal Relationships: Studies in the Production and comprehension of text. (chapter 4). Psychology Press. New York, 1997.

MARCUSCHI, L. A. Produção textual, análise de gêneros e compreensão. São Paulo: Parábola Editorial, 2008.

SANDERS, Ted J. M.; NOORDMAN, Leo G.M. The role of coherence relations and their linguistic markers in text processing. Discourse Processes, v. 29, 2000. 


\section{Como citar este artigo (Formato ABNT):}

SIMÕES, Antonia Barros G.; SILVA, Henrique M. de L.; SILVA, Danielli Cristina de L.; VASCONCELOS, Rita de Cássia F. de M. A Contribuição dos Recursos de Coesão para o Leitor durante o Processo de Construção da Representação Textual. Id on Line Revista Multidisciplinar e de Psicologia, 2018, vol.12, n.40, p.1248-1265. ISSN: 1981-1179.

Recebido: 14.05 .2018

Aceito: 18.05 .2018 